\title{
Digital Twins Development Architectures and Deployment Technologies: Moroccan use Case
}

\author{
Mezzour Ghita ${ }^{1}$, Benhadou Siham ${ }^{2}$ \\ Engineering research laboratory (LRI), System Architecture \\ Team (EAS) National and high school of electricity and \\ mechanic (ENSEM) Hassan II University, Research \\ Foundation for Development and Innovation in Science and \\ Engineering, Casablanca, 8118, Morocco
}

\author{
Medromi Hicham ${ }^{3}$ \\ Engineering research laboratory (LRI), System Architecture \\ Team (EAS), National and high school of electricity and \\ mechanic (ENSEM) Hassan II University Research \\ Foundation for Development and Innovation in Science and \\ Engineering, Casablanca, 8118, Morocco
}

\begin{abstract}
With the initiation of the fourth industrial revolution and the advent of information and communication technologies that reinforces the development of advanced technological solutions which engage data sciences, artificial intelligence, and cyber physical systems many long-established research concepts have been revived with in-depth applications within manufacturing plants. Thus currently the interest is turning more and more towards technologies and approaches that can combine between the virtual world and its increased capacities in computer sciences and processing, and the physical world with its complex systems and constantly evolving requirements. A relevant concept in this context is the concept of digital twins. Digital twins as defined by their founder Dr Michael Grieves are virtual replicas of a physical system that evolves within a virtual environment in order to mirror their real counterparts' life cycle and evolvement within the physical environment for applications in numerous domains. This paper's aim is to present a literature review of digital twin concept, its different development and deployment architectures, and its potential of application across Moroccan industrial ecosystems.
\end{abstract}

Keywords-Digital twins; industry 4.0; digital twins challenges and opportunities; Moroccan industrial context

\section{INTRODUCTION}

On the threshold of the third industrial revolution that has enabled automation to cross the doors of industrial plants in different sectors, production systems are forced today to improve not only the diversity of their product, but also the flexibility of their processes [1]. This flexibility is now sought throughout the whole supply chain moreover throughout the whole project life cycle regardless of its nature or field of application. Today's industrial world is entering a new era that requires from simulation, modeling and data management processes to be flexible, intelligent and at a real time [2], which is a challenging quest for manufacturing operations management existing methods [3]. Some of the main challenges that encounter current manufacturing and management approaches on the weir of fourth industrial revolution are related to data acquisition and processing [4], systems design and manufacturing [5], Simulation processes [6], hosting networks and communication architectures [7], plants hardware

Infrastructures adaptability, modeling [8], agility to stakeholders requirements [10], and finally performances enhancement [9]. This fourth industrial revolution has taken into application within Morocco in particular and the whole world numerous concepts and advanced technologies such as artificial intelligence, big data analysis, machine learning and concerning simulation approaches digital twins [10]. Digital twin technology represents a huge advantage for production systems and process engineering throughout products life cycle [11]. A lot of companies around the world have integrated this technology within their supply chain. Today with the emergence of digitalization and its integration within national manufacturing development plan Moroccan industrial first founded ecosystems such as OCP ecosystem decided to take this international companies path through smart and connected factories [12]. However integrating these developed technologies within plants and production systems within Moroccan context comes to be extremely challenging and requires a structured and strongly founded road map and architecture development and deployment strategies [13]. This work was developed within this context. The first section of this paper presents a state of the art of digital twin concept development throughout literature review and industrial use cases; the second section introduces a comparative study of digital twin different existing architectures. The third section based on this literature review and the application feedback discuses digital twin deployment within Moroccan industrial context. and the fourth section illustrates an application of one digital twins architectures for the development of a turbo alternator group digital twin Finally the last section summarizes the whole paper and presents future works and perspectives.

\section{StATE OF THE ART}

\section{A. A Literature Review of Concept Development}

The concept of digital twins was first introduced by Michael Grieves in one of his presentation about Product Life Cycle Management in 2003 at the University of Michigan [13], he defined it as a virtual equivalent or a replica of the physical product that requires three main parts to be established a physical product in a physical space, a virtual product in a virtual space and finally the connection between them [14]. Before introducing the term Digital Twin, the concept was referred to by Grieves as the Information Mirroring Model [11]. The National Aeronautics and Space Administration NASA used for years twining concept for its Apollo program 
in order to manage maintenance engineering operations and tests. During the design phase two replicas of the system were developed, the first one was dedicated to tests and simulations after and during the mission whereas the second one was especially dedicated to the mission. In 2010 NASA gave the definition of digital twins for predictive maintenance of space vehicles. It was introduced as a vehicles multidisciplinary simulation that make use of operational data, sensors data, functioning histories and systems physical models in order to manage space vehicles health. In 2011 the US Air Force used digital twin concept and technologies in order to management aircraft structural life prediction process [15]. In 2012 US Air force in collaboration with NASA published a paper that represented the results of a study which addressed the digital twin as a performant alternative to traditional simulation techniques for vehicles safety and reliability [16]. The aerospace industry was the first industry to introduce digital twins into its processes and products development and life cycle management through numerous industrial applications, and then other industries and fields for example automotive industry [17], integration of digital twins for real time monitoring of fleet management systems [18], urban mobility and sustainable development within smart cities [19], [20], and last but not least medicine and health care started developing and studying this technology challenges and advantages for their performances enhancement [21], [22]. Digital twin modules development and applications enhancement through literature and industry were interconnected with the development of information technologies IT and communication means and complex systems management and engineering [23]. Recently research community came with an extended four dimension vision of Grieves initial digital twin framework development [24]; this vision included four main components that are models, data, connections and services. The first dimension which is models refers to the different conceptual models that draw the first lines of the digital twin design. Within advanced simulation process mainly development project of digital twin, modeling plays a primordial role, in the sense that it's the starting point for launching a simulation. Modeling enables simulator and project stakeholders to understand the complex system their working on, its behaviors, states and interactions with its environments. The first step for establishing a simulation program is the modeling of real system components and driving functions .Modeling create a bridge between the real system its different parameters, constraints, data and the simulation program [25] simulation process start with an elaborated study of the real system, the establishment of its conceptual model, then development of simulation program and finally analysis of simulation results. The second dimension shed light on data of the digital twin which is a crucial aspect that enables digital twin not only to interact with its virtual space but also with the physical asset and its physical space, with project stakeholders and finally with external environment changes and constraints. Digital twin can be alimented with data from the physical systems such as functioning histories, field real time measurements and parameters performances, with external decisions imposed by stakeholders and due to the integration of machine learning to its personal knowledge base and memory [26]. The third- dimension concerns communication technologies and protocols between systems, spaces and models. Notable effort has been done in the recent years concerning this aspect in order to improve real-time monitoring of equipments and assets, data acquisition and processing, and last but not least models interoperability and simulation synchronization time [27]. The last dimension within the new proposed vision is services intended from the established digital twin development and deployment project. Services refers to digital twin features in order to meet stakeholders and context requirements [28]. Digital twin has proved through its different industrial applications its efficiency in handling a multitude of functions such as product health management (PHM), state prediction, energy consumption optimization [29], real time monitoring and so many others applications within different sectors that will be detailed in further parts.

\section{B. Digital Twin Development and Deployment Architectures within Industry 4.0}

Throughout literature and different industrial use cases a multitude of architectures had been proposed in order to create a framework for digital twins' development and implementation. These architectures varied depending on digital twins' field of applications, intended services and benefits and related technologies and concepts. This part focuses on the analysis of these architectures background, key concepts, challenges, opportunities and cyber physical data lifecycle management. The analysis of the different proposed architectures and the review of reference architectures for intelligent and autonomous systems [26] enabled us to conclude on a common reference representation for digital twin development and implementation architectures which is based on three layers. The first layer consists on industrial layer that includes field complex physical systems which can be a production line, an equipment or the whole industrial installation. This layer composition depends strongly on digital twin scope and physical twin environment. The second layer is application layer that focuses on digital surrogates' main cyber components and features. Finally the third layer is communication layer that enables cyber physical interactions. Based on our literature review and our analysis of a large number of application use cases in various fields, we have tried to nourish these different layers and to conclude on different existing digital twins' implementation and development architectures. Fig. 1 summarizes the proposed digital twin reference architecture and figure 2,3,4,5,6 and 7 put into effect this representation within the fourth industrial ecosystem.

1) Development architecture based on the fusion of digital twin concepts and big data principles: The fusion between big data and digital twin can result on the development of cyber physical data that can allow smart manufacturing approaches and benefits from highly developed big data techniques to improve and enlarge digital twin applications and services [27]. Some of the advantages that digital twin can brings to big data field concerning data variability is digital twin ability to generate new information's through virtual models and real time connection to operational and legacy data. In the sense that surrogates virtual models can through their interactions with the physical space and real systems performances 
generate a variety of predictive models directly related to the virtual twin. These predictive models can help maintenance staff to detect root causes of some failures and prevent some complex systems unpredictable behaviors [21]. The other way round big data provides digital twins with some advanced data cleaning, mining and analysis techniques that can enable the improvement of product life cycle management [22]; asset health management [28], production planning and other manufacturing critical operations that will be discussed further in this paper. Fig. 2 concretizes this vision resulting architecture.

2) Development architecture based on Augmented Reality $(A R)$ and Virtual Reality (VR): When combined with digital twin basic concepts augmented reality can bring a lot of advantages for different domains mainly predictive maintenance, systems design and operators training. Augmented and virtual realities are both concepts that establish continuous connections between physical and virtual world but also dynamic interactions between complex systems stakeholders, components and virtual twins. The use of augmented reality for digital twins deployment and exploitation within factories enables the application of numerous complex and critical tasks within the physical space with virtual assets. The fusion of digital twins and augmented reality was applied for numerous applications in the industrial field. For example maintenance operations management [29], distant process control, and within education field for attaining learning objectives [30]. These large set of different and diversified applications had proven the efficiency of this combination. Fig. 3 represents the proposed architecture for this amalgamation.

3) Devellopement architecture based on Industrial Internet of Thing concepts (IIoT): Digital twin and industrial internet of things (IIOT) combination can presents some notable benefits for cyber physical systems development framework [31]. Industrial IoT enables systems large scale connection as well as external connections [32]. IIOT advanced communication capabilities are crucial for unleashing digital twin solutions potential. On the one hand Industrial IoT architectures encourages exchange between different levels and elements its enable reliable and safe interactions with physical smarts objects and systems. On the other hand digital twin concept through exploiting data gathered with IoT gateways and components can give ergonomic virtual representations for users and offers for systems data analytics smart, embedded, and performant algorithms and tools [33]. Fig. 4 represents the different layers of the proposed architecture within this framework.

4) Development architecture based on complex systems engineering: The emergence of industry 4.0 concepts and visions has bring a lot of new requirements and functions to engineering and manufacturing[34]. With the spread of new paradigms such as cyber physical systems, digital twins that is a key concept for virtual and physical world fusion has gained a lot of interests [30]. The development and implementation of digital twins within factories despite the different technologies offered by advanced technologies and solutions vendors encountered a lot of challenges concerning digital twin effective deployment within manufactories [31] hence comes the importance of developing an organized and well founded framework for digital twins. Complex systems engineering has been a key tool for complex physical systems development [35]. A lot of methods and languages had been developed in order to exploit this method effectively. These tools offer a modeling and simulation dynamic framework for digital twins One of these languages is Systems Modeling Language SYSML that offers numerous diagrams for digital twin functional and behavioral development and that have been used in some digital twins applications [32]. By using complex system engineering digital twin external and internal stakeholders will interact actively in order to develop an autonomous and performant system that fits their technical and non technical needs and requirements [13]. Fig. 5 illustrates the architecture resulting from this collaboration.

5) Development architecture based on cloud services: Cloud computing and cloud services has gained a lot of popularity among industrials from different sectors lately [33]. Today cloud platforms provide in addition to storage and computing services a lot of others features that can foster manufactories management operations [36]. Lately digital surrogates development and deployment has been added to this broad portfolio of services [28]. The main idea behind this contribution from Oracle point of view for example is to ensure better visibility, accurate prediction, efficient documentation, real time communication management and last but not least integration of disparate heterogeneous systems [37]. A lot of cloud computing services vendors had proposed architectures for digital twin development and deployment such as Amazon, Microsoft Azure and Oracle. These architectures were developed with the combination of cloud computing, IoT concepts as well as augmented Reality for some use cases [38]. For example Amazon through AWS IoT Core offers assets shadows service [39]. The shadow service enables users to connect their devices to the cloud and create their devices twins within a dedicated platform in Amazon cloud. The shadow will record physical devices status on a JSON format available for consultation and shares it for analysis with other cloud services and clients. The service gives client the ability to configure different shadows parameters such as access, documentation, updates, desired states and many other options. Fig. 6 concretizes this vision.

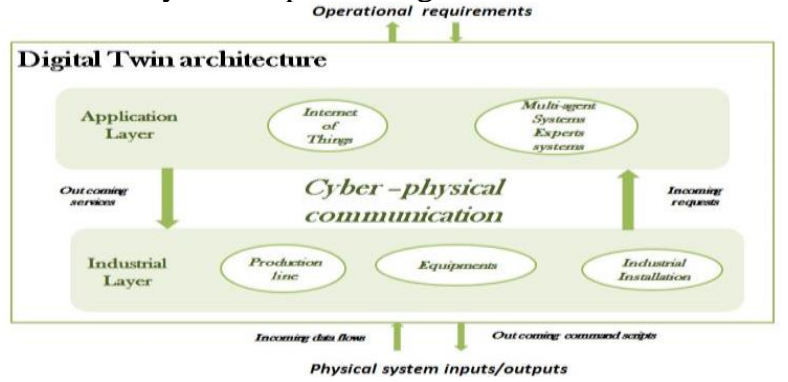

Fig. 1. Digital Twin Development and Deployment Architecture Layer. 
Extemal environment factors and requirements ( competitivity ,

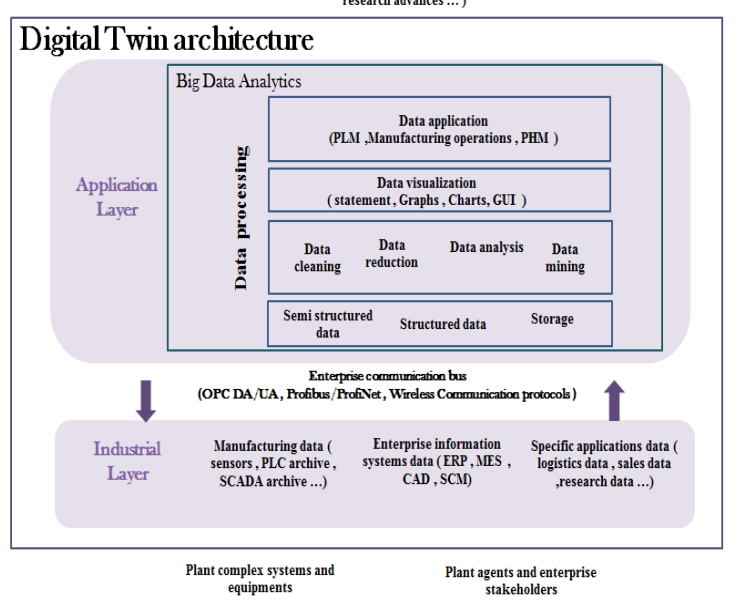

Fig. 2. Digital Twin Architecture based on Big Data.

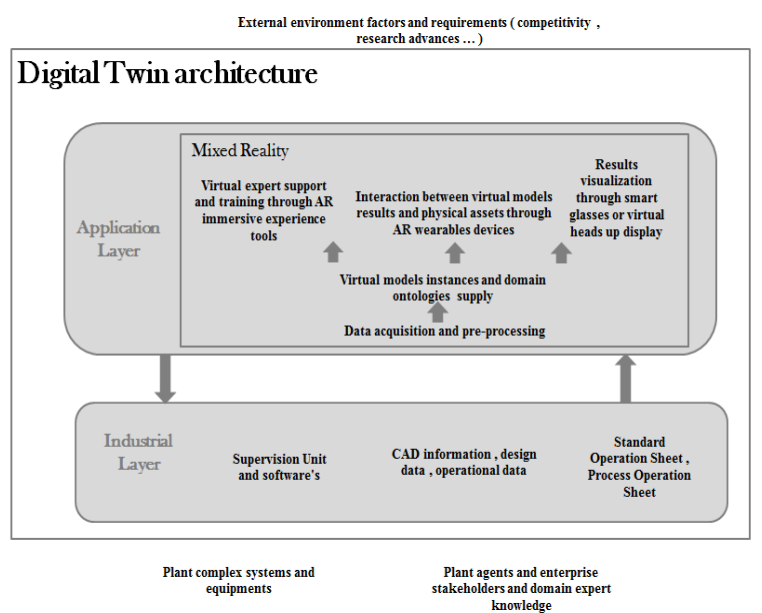

Fig. 3. Digital Twin Architecture based on Mixed Reality.

External environment factors and requirements ( competitrity ,

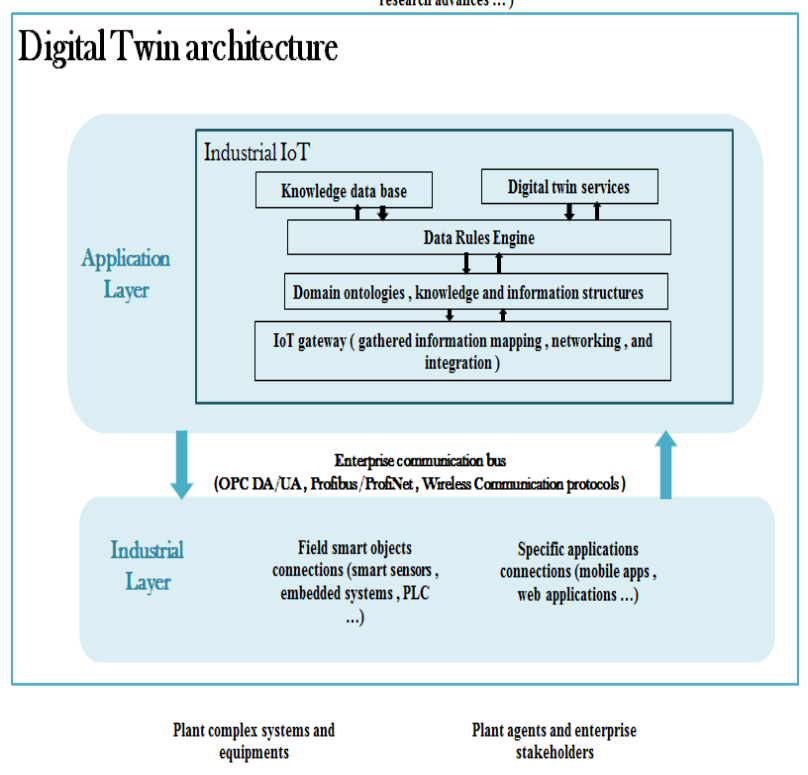

Fig. 4. Digital Twins Architecture based on Idustrial Internet of Things.
Esternal environment factors and requirements ( competitivity

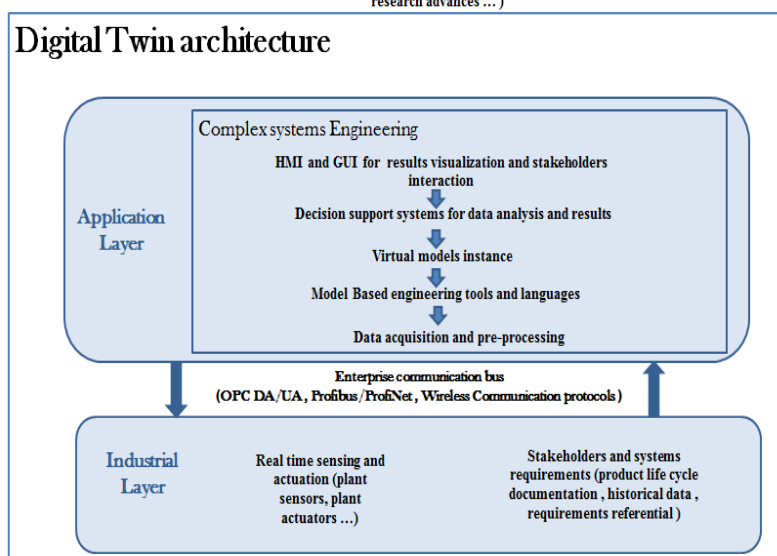

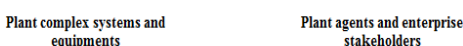

Fig. 5. Digital Twin Architecture based on Complex System Engineering.

External environment factorsand requirements ( competitivity ,

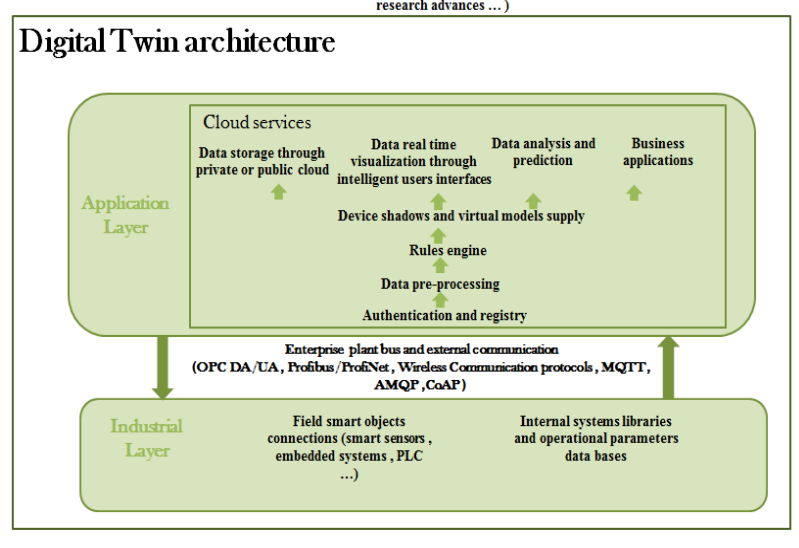

Plant complex systems and $\quad$ Plagents and enterprise
satseholders

Fig. 6. Digital Twin Architecture based on Cloud Services.

External environment factors and requirements ( competitivity ,

\section{Digital Twin architecture}

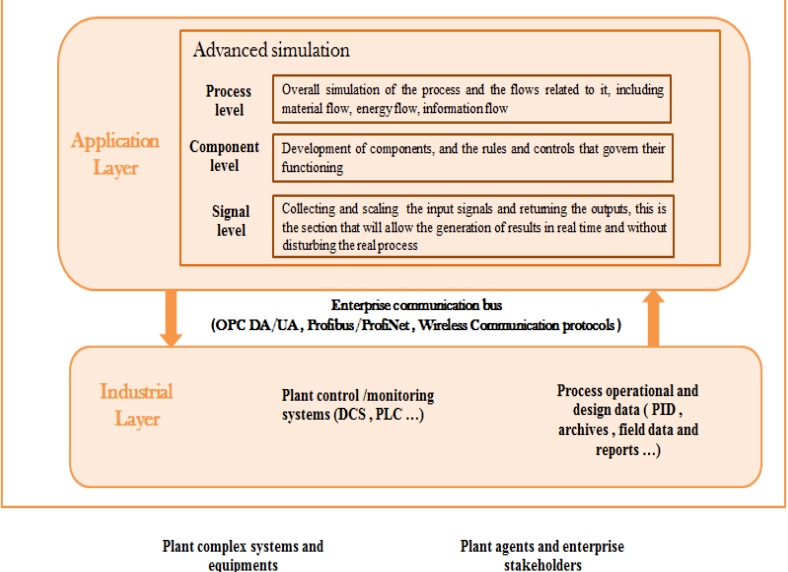

Fig. 7. Digital Twins Architecture based on Advanced Simulation Techniques. 
6) Development architecture based on advanced simulation techniques: A lot of research organism such as NASA and US Air force exploited digital twin concept with the use of simulation for manufacturing process and prototyping operations enhancement, predictive maintenance, product life cycle management [14]. Through its combination with existing simulation tools or by developing a whole new framework such as Digital Thread concept as proposed by US Air Force [40]. This new simulation framework will be based on knowledge management, vertical and horizontal integration and the integration of all interactions with external ecosystem [41]. Currently a lot of simulation software vendors provide technologies that are founded on the basis of digital twin concept [32]. Whether it's through simulation software's, other simulation tools and their combination with data management tools, modeling techniques and information and communication techniques digital twin represents numerous opportunities for real time simulation techniques development and deployment within manufactories [42]. Fig. 7 illustrates digital twin architecture based on advanced simulation techniques and technologies.

\section{Digital Twin Development and Deployment Technologies}

There are numerous companies in different fields that developed and deployed digital twin concept through their manufactories in order to improve their performances. According to their core business, field of applications and services intended from the digital twin each of these companies gave it a particular definition. For example the first sector concerns use cases of companies that operate in the field of electric power generation such as Siemens [34] [35], Honeywell [36], Shneider Electric [37], General Electric GE [38],[39], the second ones are companies that offer digital and IoT services like Parametric Technology Corporation PTC [40] ,Amazon, IBM, DELL and the third one automotive entreprises like PACCAR, and aviation industry such as GE Aviation Systems LLC [41]. In addition to these technologies a lot of patents [42] and international reports concerning digital twins concept effective deployment and their application within manufactories and other fields were published in recent years [43], [44]. The thing that once again reinforces their position as en efficient tool and a promising concept for both research and industry.

\section{Digital Twin Development and Implementation Related Standards}

In recent years many standards have been developed to support the deployment and implementation of industry 4.0 and cyber and physical systems connections new technologies and tools such as digital twins[[45],[46],[47]]. The literature review in reference to the different architectures founded for the implementation of digital twins has enabled us to identify a number of significant standards and referential that relate to each of the layers of the architectures proposed. All these standards are not specific to digital twins' global development framework and do only address one of the aspects connected to the digital twins adopted architectures. In 2018 the Technical Committee ISO/TC 184/SC 4 proposed a standard development project specifically dedicated to the framework of digital twin development and implementation, this standard is currently being elaborated and its appearance is foreseen for the next few year [48]. Some of these standards are listed below and will be detailed furthermore. Standards description is divided into four categories industry 4.0 global framework standards; industrial layer related standards; application layer related standards and finally physical and digital communication related standards. This classification is inspired by the Reference Architecture Model for industry 4.0 (RAMI4.0) proposed segmentation for architecture 4.0 framework [49] and International standards Organization (ISO) International Classification for Standards (ICS) 35.240.35 standards family for IT application in industry. The first category deals with global framework standards firstly standards that concerns smart factory implementation guide lines and requirements it is introduced by IEC 62794 that defines a reference model for digital factory development and integration and IEC 62832 that highlights the general principles fir digital factory pillars integration through the automation architecture. And finally RAMI 4.0 that is a reference guide line for industry 4.0 [50].

Secondly this category includes standards on digital twin ecosystem global security development [31] mainly ISO 27000 families for information systems layers security and risks management, DIN SPEC that details IT security techniques based on domain expert definition, IEC 61850 for automation systems advanced protection and finally IEC 62443 for industrial automation and control systems security [51]. Industrial layer related standards list a number of standards that relates to raw data structure and exploitation references techniques, smart asset and device management under 4.0 architectures and finally knowledge management requirements throughout different affiliated norms respectively ISO/TS 18876-2:2003, ISO/IEC 30101:2014; IEC 62264 and ISO 30401:2018. Application layer introduces standards related to the different concepts and architectures for digital twin development mainly big data-based architecture through ISO/TEC 19395 that define best practices for data center resources monitoring and control and ISO/IEC WD 27045 for security concerns within big data field which is a critical element for digital twins' deployment within industrial plants. Industrial IoT based architecture introduces main standards of IoT implementation and global concepts for its understanding through ISO/IEC TR 22417:2017, IEEE P241, ISO/IEC NP 30166 and finally ISO/IEC 21823-1:2019. This parts also shed light on an important component of digital twin implementation that is visualization and which can be apprehended through human machine interaction standards and ergonomic standards.

Communication layer which is a crucial element for digital twin efficient exploitation introduces communication standards related to virtual and physical connection [27] mainly DIN SPEC that gives guide lines for AML and OPCUA integration, IEC 62601:2015 for wireless communication within industrial plants and RESTFUL -API related standards and referential as its one of the most used communication protocol for physical and virtual layers connection.A lot digital twins applications across literature and for some propose digital twins technologies used OPC UA and Automation ML [52]. 


\section{SYNTHESIS AND COMPARISON}

\section{A. Synthesis}

All over the literature and the various industrial use cases discussed along the previous section, a plethora of architectures have been proposed to create a framework for the development and implementation of digital twins, depending on the scope of application of digital twins, the services and benefits intended and the architectures associated technologies and concepts. This section summarizes the results of the analysis conducted on the main foundations of each of the architectures detailed in the previous section. Digital transformation has brought a lot of concepts to application within automation-based plants these concepts evolvement can contribute a lot for digital twins' deployment and development. Throughout their main components and key technologies that highlights the major impact of information and communication technologies and computer sciences on automation and industries performances improvement and efficiency. The focus on providing ecological, performant but less expensive technological solutions when it comes to cloud services, big data or IoT can be exploited to create and propose innovative digital twins' architectures and technologies.

\section{B. Architectures Comparasion}

Throughout literary review of digital twins we were able to identify a number of factors that occur in the process of adapting one of the architectures mentioned above to efficiently exploit the potential of digital twin concept [53]. Thus we distinguished two categories of factors for architecture suitability assessment. The first category concerned factors related to the contextual adaptability of the architecture in order to develop context aware digital twins. And the second category is constituted by factors related to architectures functional suitability [54] once the twin in question is deployed. The first category that concerns contextual adaptability includes five elements, multi-agent interoperability, project management, energy management, security management, and finally data life cycle management. The second category that is concerned with functional adaptability and it includes digital twin implementation architectures hardware and software layers functional suitability evaluation. This differentiation has many advantages for a digital twin development and deployment project, particularly in an evolving industrial context that is characterized by several requirements on different levels and that needs agile management methods [55],[56].

\section{Digital Twins DeVElopment AND IMPLEMENTATION ARCHITECTURE -MOROCCAN USE CASE}

\section{A. Opportunities and Threats}

Morocco is currently in the midst of a revolution to integrate digital transformation in several sectors, primarily education, public administration and the industrial ecosystem through its actors[57]. This transition requires the collaboration of several entities, including not only research institutions but also the internal entities of the industrial tissue [58].

A crucial element for the integration of industry 4.0 concepts of which digital twins [59], and particularly to the
Moroccan industrial context are change management strategies. Change management strategies should not only affect the internal structure of companies but also training systems and management practices at the strategic and operational levels of the country. Many studies in recent years have been conducted for the development of these aspects within Morocco with regards to the integration of industry 4.0 and its elements such as artificial intelligence, big data ,cloud computing [10] more essentially smart cities [60] and their numerous applications and challenges [61]. Inspired by these studies and internal and external reports on 4.0 technologies [57],[58], [62] and the implementation of digital twins at the international level, we were able to gather a set of strengths and weaknesses related to Moroccan context and opportunities and threats related to the external context. This analysis concerned the adaptability of current context for implementing the various digital twin architectures concluded from the state of the art on concept development and its relationship with the evolvement of industry 4.0. This study has allowed us to identify some major development axes for the integration of digital twins within Morocco that will be further strengthened through several other context studies and surveys. The various strengths and opportunities that we have been able to conclude offered us a basis for the development of a high-performing digital twin architecture that could use experience feedback from international experiences on this subject to develop an adaptability mechanism specific to the Moroccan context Thus this mechanism main role is to link between computer centric development methods and human centric development methods to propose a generic framework for the development of context aware digital twins. Table I summarizes the results of SWOT analysis. These analyses were established in order to assess the potential of existing digital twins' development and deployment architectures.

\section{B. Application use Case}

1) Global context: This project is a part of OCP's Mining Digitization Initiative. since the emergence of industry 4.0 technologies OCP have been known as one of the first Moroccan enterprises that tried to integrate these technologies within their plants [12]. Digital twin's technology that is one of the most spread industry 4.0 technologies offers numerous applications and features for operation management improvement, advanced process control and collaborators training techniques evolvement. Thus, it considered as one of the pillars for industrial field digital transformation from installation and processes automation to the development of industrial plants cyber physical systems. The project first use case presented through this paper consisted on the development of a digital twin for the turbo alternator group of the thermal power plant in OCP's Jorf fertilizer Company 5 (JFC5) utilities facility with the collaboration of the different stakeholders. The main purpose of this project was the development and improvement of the group performances and the development of a simulation platform 4.0 improvement of the group performances and the development of a simulation platform 4.0 specific to the OCP group, throughout refining 
industrials needs and evaluating the proposed digital twin technology adaptability to context requirements.

TABLE. I. SWot ANALYSis For DigitAl Twins ARCHITECTURES DEPLOYMENT

\begin{tabular}{|c|c|c|c|c|}
\hline SWOT analysis & Strengths & Weaknesses & Opportunities & Threats \\
\hline $\begin{array}{l}\text { Development architecture } \\
\text { Based on the fusion of } \\
\text { twin digital concepts and } \\
\text { Big data management }\end{array}$ & $\begin{array}{l}\text { There is a great interest in data } \\
\text { management with all its aspects } \\
\text { Availability of a solid and developed } \\
\text { software and hardware infrastructure } \\
\text { Deployment of several research } \\
\text { projects on the development of } \\
\text { internal knowledge management } \\
\text { Feedback from internal application } \\
\text { cases on problems encountered }\end{array}$ & $\begin{array}{l}\text { Confidentiality requirements } \\
\text { Delays in the time required } \\
\text { to implement solutions } \\
\text { related to the architecture } \\
\text { Challenges of } \\
\text { interoperability with existing } \\
\text { data management and } \\
\text { analysis systems }\end{array}$ & $\begin{array}{l}\text { Publication of several standards } \\
\text { structuring the development of } \\
\text { this type of architectures } \\
\text { Numerous and diverse } \\
\text { bibliographic sources and } \\
\text { application cases Several } \\
\text { contextual parameters and } \\
\text { requirements such as hardware } \\
\text { energy consumption and software } \\
\text { security are already taken into } \\
\text { account }\end{array}$ & $\begin{array}{l}\text { Cyber security risks } \\
\text { National regulations } \\
\text { and standards }\end{array}$ \\
\hline $\begin{array}{l}\text { Development } \\
\text { architecture based on } \\
\text { Industrial Internet of } \\
\text { Things }\end{array}$ & $\begin{array}{l}\text { Digitization is a strategic national } \\
\text { priority The initiation of different } \\
\text { knowledge capitalization and data } \\
\text { management projects -Feedback and a } \\
\text { microscopic and macroscopic view of } \\
\text { the landscape within morocco } \\
\text { Networking infrastructure in progress } \\
\text { The availability of advanced ICTs }\end{array}$ & $\begin{array}{l}\text { Difficulties of integration - } \\
\text { Need to carry out several } \\
\text { risk studies to assess the } \\
\text { potential of the solution, in } \\
\text { the field of security in in } \\
\text { particular High short-term } \\
\text { costs Resilience to change } \\
\text { Interoperability with legacy } \\
\text { systems and Ergonomics } \\
\text { concerns Hostile } \\
\text { implementation } \\
\text { environments }\end{array}$ & $\begin{array}{l}\text { Field expert facility } \\
\text { implementation within Morocco - } \\
\text { Partnership with several research } \\
\text { organizations dedicated to the } \\
\text { development of IIoT solutions } \\
\text { Accessible experience feedback } \\
\text { Development of the IIoT } \\
\text { solutions standards framework } \\
\text { Field in continuous evolution in } \\
\text { Morocco and competence } \\
\text { development within the sector }\end{array}$ & $\begin{array}{l}\text { Dependency towards } \\
\text { solution providers' } \\
\text { Insufficient regulation } \\
\text { and national } \\
\text { guidelines Security- } \\
\text { related risks } \\
\text { Accessibility risks } \\
\text { (network, equipment, } \\
\text { etc.) Worldwide } \\
\text { rapid growth }\end{array}$ \\
\hline $\begin{array}{l}\text { Development and } \\
\text { deployment architecture } \\
\text { Based on Cloud } \\
\text { Computing CC and } \\
\text { Cloud Services CS }\end{array}$ & $\begin{array}{l}\text { High energy saving compared to other } \\
\text { technologies especially for large } \\
\text { enterprises that needs a lot of } \\
\text { computing and storage resources } \\
\text { Flexibility and portability Reducing } \\
\text { hardware costs and implementation } \\
\text { delays }\end{array}$ & $\begin{array}{l}\text { Increased security } \\
\text { requirements and favoring } \\
\text { the use of private cloud } \\
\text { technologies High } \\
\text { dependency to cloud } \\
\text { provider Lack of national } \\
\text { regulation directly related to } \\
\text { cloud computing activities } \\
\text { management Reticence with } \\
\text { regard to data sharing } \\
\text { Insufficient mastery of the } \\
\text { concept Needs of high } \\
\text { performance networks and } \\
\text { communication technologies }\end{array}$ & $\begin{array}{l}\text { National awareness of the } \\
\text { potential of the cloud and its } \\
\text { services Worldwide regulation } \\
\text { and consolidation of the cloud } \\
\text { computing industry Existence of } \\
\text { national feedback and internal } \\
\text { case study on cloud exploitation } \\
\text { Approval of several standards } \\
\text { projects on cloud computing }\end{array}$ & $\begin{array}{l}\text { Cybersecurity } \\
\text { concerns High } \\
\text { dependency to cloud } \\
\text { provider Lack of } \\
\text { national regulation } \\
\text { directly related to } \\
\text { cloud computing } \\
\text { activities managemen }\end{array}$ \\
\hline $\begin{array}{l}\text { Development and } \\
\text { deployment architecture } \\
\text { based on advanced } \\
\text { simulation techniques }\end{array}$ & $\begin{array}{l}\text { Structured control and monitoring } \\
\text { architecture Maturity } 3.0 \text { and } \\
\text { automation under development } \\
\text { Control and monitoring systems open } \\
\text { to modifications High-performance } \\
\text { field communication protocol } \\
\text { Availability and accessibility to the } \\
\text { expertise of different suppliers } \\
\text { Development of advanced automation } \\
\text { data management }\end{array}$ & $\begin{array}{l}\text { Difficulty of adaptability } \\
\text { and interoperability with } \\
\text { legacy control command } \\
\text { systems Difficulty in } \\
\text { accessing the histories of } \\
\text { existing data Complex } \\
\text { systems and modelling- } \\
\text { related difficulties } \\
\text { Adaptability and mastering } \\
\text { challenges }\end{array}$ & $\begin{array}{l}\text { Domain in a state of very high } \\
\text { speed evolution Development of } \\
\text { high-performance computing and } \\
\text { storage tools -Variety of } \\
\text { proposed technologies and } \\
\text { extension to several cases of } \\
\text { industrial environments }\end{array}$ & $\begin{array}{l}\text { Security risks with } \\
\text { high levels of } \\
\text { criticality Reticence } \\
\text { to data sharing } \\
\text { Energy consumption } \\
\text { constraints } \\
\text { Compliance with } \\
\text { regulations }\end{array}$ \\
\hline $\begin{array}{l}\text { Development and } \\
\text { deployment architecture } \\
\text { Based on Complex } \\
\text { systems engineering }\end{array}$ & $\begin{array}{l}\text { Multidisciplinary and constantly } \\
\text { collaborating engineering and } \\
\text { research teams to explore advances } \\
\text { related to the different core businesses } \\
\text { of companies Low investment } \\
\text { required for the hardware layer to } \\
\text { implement the solution Development } \\
\text { of the knowledge management } \\
\text { component and data management } \\
\text { techniques within companies } \\
\text { Capitalization of expertise and } \\
\text { communication is becoming one of } \\
\text { the strategic objectives of the country } \\
\text { recently }\end{array}$ & $\begin{array}{l}\text { Difficulty in modeling and } \\
\text { uniformizing models for } \\
\text { large structures based on } \\
\text { automation layers provided } \\
\text { by different vendors } \\
\text { Confidentiality and IT } \\
\text { security constraints } \\
\text { Reluctance towards public } \\
\text { data sharing Resiliency to } \\
\text { change Difficulty in } \\
\text { capitalizing knowledge and } \\
\text { accessing data for existing } \\
\text { installations Adaptability } \\
\text { of internal infrastructure } \\
\text { Long product lines } \\
\text { development times }\end{array}$ & $\begin{array}{l}\text { Availability of scientific and } \\
\text { industrial feedback -Development } \\
\text { of Model Based Engineering and } \\
\text { its tools National Digitalization } \\
\text { Strategy Development of a high- } \\
\text { performance open source } \\
\text { platforms for data modeling and } \\
\text { visualization Training } \\
\text { increasingly oriented towards the } \\
\text { use of advanced modelling and } \\
\text { simulation tools Development of } \\
\text { network and telecommunications } \\
\text { infrastructure throughout the } \\
\text { country's provinces }\end{array}$ & $\begin{array}{l}\text { Difficulty in keeping } \\
\text { up with developments } \\
\text { in the field at the } \\
\text { international level } \\
\text { Conformity with } \\
\text { national regulations } \\
\text { Changeable market } \\
\text { requirements and } \\
\text { needs }\end{array}$ \\
\hline
\end{tabular}


TABLE. II. ARCHITECTURES COMPARATIVE STUDY

\begin{tabular}{|c|c|c|c|c|c|c|c|c|}
\hline Criteria & Sub criteria & Factors for assessment & A1 & A2 & A3 & A4 & A5 & A6 \\
\hline \multirow{20}{*}{$\begin{array}{l}\text { Context } \\
\text { adaptability }\end{array}$} & \multirow{3}{*}{$\begin{array}{l}\text { Energy } \\
\text { management }\end{array}$} & Hardware and software energy consumption regards & & & & & & \\
\hline & & Compliance to energy management strategies within the company & & & & & & \\
\hline & & Energy management indicators and possible assessment & & & & & & \\
\hline & \multirow{4}{*}{$\begin{array}{l}\text { Data } \\
\text { management }\end{array}$} & $\begin{array}{l}\text { Compliance with existing data structures and representations (supported forms, supported } \\
\text { representations, supported data volume) }\end{array}$ & & & & & & \\
\hline & & Compliance with national data sharing process regulations and laws & & & & & & \\
\hline & & Performant data acquisition and preprocessing platforms & & & & & & \\
\hline & & Data modeling (unified semantics, unified interfaces) & & & & & & \\
\hline & \multirow{4}{*}{$\begin{array}{l}\text { Multi-Agent } \\
\text { interoperability }\end{array}$} & Legacy systems interoperability & & & & & & \\
\hline & & Agents and collaborators access & & & & & & \\
\hline & & Solution usability and ergonomic & & & & & & \\
\hline & & Solution trustworthiness and technology freedom of context risks & & & & & & \\
\hline & \multirow{3}{*}{$\begin{array}{l}\text { Security } \\
\text { management }\end{array}$} & $\begin{array}{l}\text { Compliance of industrial layer security management mechanisms with project } \\
\text { stakeholders' requirements and solution potential risks within the project context }\end{array}$ & & & & & & \\
\hline & & $\begin{array}{l}\text { Compliance of communication layer security management mechanisms with project } \\
\text { stakeholders' requirements and solution potential risks within the project context }\end{array}$ & & & & & & \\
\hline & & $\begin{array}{l}\text { Compliance of application layer security management mechanisms with project } \\
\text { stakeholders' requirements and solution potential risks within the project context }\end{array}$ & & & & & & \\
\hline & \multirow{2}{*}{$\begin{array}{l}\text { Project } \\
\text { management }\end{array}$} & Human capital management & & & & & & \\
\hline & & Project costs and budget management & & & & & & \\
\hline & \multirow{4}{*}{$\begin{array}{l}\text { Conformity } \\
\text { management }\end{array}$} & $\begin{array}{l}\text { Existence of international and national feedback, references and standards for the } \\
\text { solution scope }\end{array}$ & & & & & & \\
\hline & & Existence of certified use cases on technology exploitation and deployment & & & & & & \\
\hline & & Compliance with national regulation and standards & & & & & & \\
\hline & & Compliance with enterprise internal standards & & & & & & \\
\hline \multirow{12}{*}{$\begin{array}{l}\text { Functional } \\
\text { suitability }\end{array}$} & \multirow{5}{*}{$\begin{array}{l}\text { Hardware } \\
\text { suitability }\end{array}$} & Compliance with existing control command architecture & & & & & & \\
\hline & & Compliance with plant communication infrastructure & & & & & & \\
\hline & & Independency from vendors possibility & & & & & & \\
\hline & & Compliance with plant hostile environments (data acquisition hardware immunity & & & & & & \\
\hline & & Hardware implementation delays and costs & & & & & & \\
\hline & \multirow{7}{*}{$\begin{array}{l}\text { Software } \\
\text { functional } \\
\text { suitability }\end{array}$} & Software appropriateness with regards to project stakeholders' requirements & & & & & & \\
\hline & & Software correctness with regards to project stakeholders' requirements & & & & & & \\
\hline & & Software completeness with regards to project stakeholders' requirements & & & & & & \\
\hline & & Software portability & & & & & & \\
\hline & & Software efficiency & & & & & & \\
\hline & & Software compatibility with legacy systems & & & & & & \\
\hline & & Software maintainability & & & & & & \\
\hline
\end{tabular}

2) Project stakeholders research organization: In order to create a bridge between research and industry, research organizations mobilize groups of engineers from different specialties who have acquired during their studies a set of basic concepts allowing them to easily integrate both industrial and research environments. The main purpose of these groups is to search for advances within enterprises core business context the mining sector and their principal mission is to understand the new proposed technologies and practices in order to improve them and adapt them to the context of their application. Thus, for this stakeholder, the project will serve as a springboard between research and development.

Industrial in the mining sector: For the industrial sector, the main objective is to improve its processes and consequently the quality of its supply chain and, in a more global vision, its competitiveness in terms of its DAS. To achieve this objective, it is essential to stay up to date with new technologies that have the same purpose. Supplier of simulation technologies and engineering team: Today on the market a wide range of companies offers several simulation technologies and software 
to meet industrialist needs. Supplier's and internal engineering team goal is to meet specific needs and requirements in terms of performances and creativity.

\section{Turbo Alternator Group Digital Twin}

1) Architecture selection and technlogy adaptability: The choice of digital twin development and deployment architecture was strongly related to context constraints, stakeholders' requirements and technology functional suitability. Table II represents the results of the six proposed digital twin architectures selection based on a set of criteria that were developed in collaboration with project engineering team and based on users initial set of digital twin functional and operational requirements and context adaptability factors. The first architecture (A1) evaluated through the criteria defined is IIOT based architecture, the second one (A2) is big data based architecture, the third one (A3) is mixed reality based architecture, the fourth one (A4) is simulation based architecture, then (A5) complex systems based architecture and finally the last one (A6) is cloud computing based architecture. The evaluation of the different criteria for the six architectures proposed was based on context parameters and stakeholders' requirements towards digital twin solution development and deployment. Criterion evaluation was through three levels the first level represents high compliance with required criterion, the second level is medium compliance; and the last level represents low or non-existent compliance.

2) Digital twin development and implementation: Based on the different models developed through the different foundations defined and operational data preprocessing we were able to supply SIMIT simulation three levels, signal level, component level and process level [63]. The simulation results and test conducted through the three levels enabled us to verify and validate the twin virtual components models. The models developed will be shaped through the record-keeping of the obtained simulation results and their correlation with the actual installation properties. This ongoing process, which links the digital twin to his real compatriot, will enable him to create his own training data set. Fig. 8 represents the twin developed user interface for simulation and tests. Fig. 9 introduces foundations for turbo alternator digital twin development based on architectures comparison results.

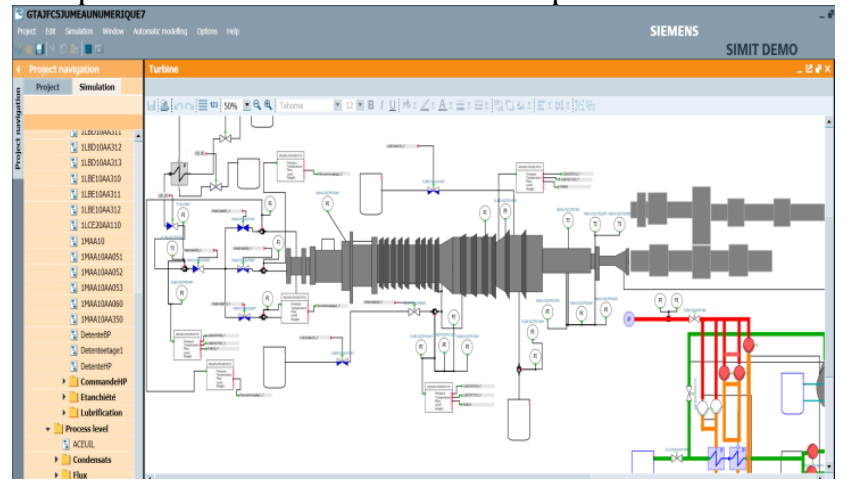

Fig. 8. Digital Twin Process Simulation and Tests Interface.

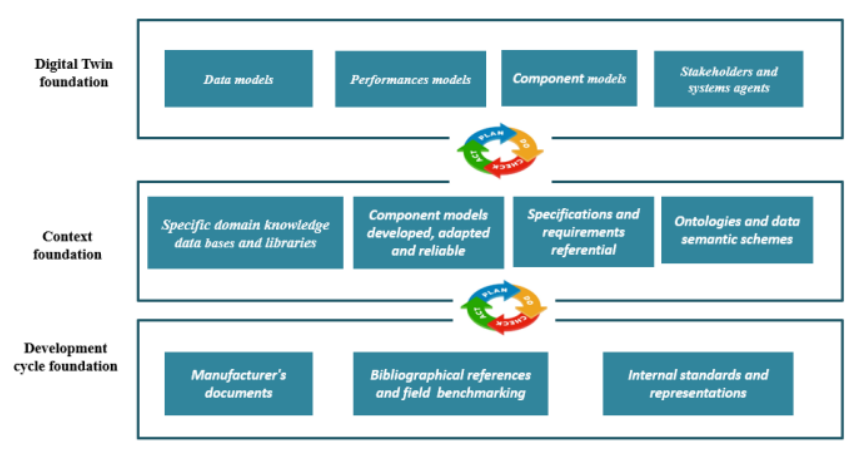

Fig. 9. Digital Twin Development Foundations.

\section{CONCLUDING REMARKS AND FUTURE}

Through this paper and our literature review on the field we tried to give an overview of the roots of digital twin concept, its different fields of application, its development and deployment architectures, and the technologies offered by different market vendors that mainly consist on the exploitation of the concept foundations. The use case of application we worked on enabled us to detect some of the limitations and challenges that can hinder digital twins deployment despite the large set of opportunities it represents for the development of a lot of research axes for example predictive maintenance and real time monitoring. These limitations that were highlighted previously by architectures comparison and SWOT analysis concerned some of the main problematics of new technologies implementation within manufacturing plants. Mainly these problematics concern hardware infrastructures maturity and their adjustment costs and delays to meet the technical requirements of new technologies, modeling challenges, cyber security, interoperability and last but not least human capital competencies. In order to ensure these advanced technologies deployment industrialists have to afford a communication bridge with different research communities that based on experience feedback can work on scalable and generic solutions that can practically encompass these identified obstacles. It's crystal clear that in the last decade due to the emergence of a lot of new information and communication technologies and the evolvement of industry 4.0 vision, the interest towards digital twins within both research and industrial eras has significantly arise. The new shift towards cyber physical systems has resulted on the emergence of a new technological decade that makes computer sciences, communication technologies and cognitive sciences in the focus of numerous manufacturing ecosystems. The great impact that artificial intelligence has on the evolvement of a lot sectors that are related to industrial fields as well as other social aspects makes us think about the opportunities that can be offered by the combination of digital twin concepts with artificial intelligence areas like machine learning or deep learning so as to support its efficient implementation. Currently some of the technologies developed by digital services vendors like Microsoft or IBM are exploiting the potential of artificial intelligence for applications within smart factories, and digital twins' development. Our future works will focus on the exploration of this aspect with relationship to existing applications and potential opportunities offered to digital twin concept within Moroccan context that highlighted 
a lot of problematics related to the concept deployment as mentioned previously. Throughout surveys conducted with industrialists from different sectors and the exchange of scientific, industrial and normative experience feedback, we intend to develop an evaluation framework for digital twins. This framework through existing applications as well as gathered good practices and procedures learnt on the subject, will allow us to propose a holistic architecture for the development of digital twins that can overcome the previously identified limitations but also benefit from the technological advances of Industry 4.0 and researches conducted for its effective implementation not only as a strategic vision but also as an action plan for accelerating the performances of manufacturing plants.

\section{ACKNOWLEDGMENT}

This research was supported by Mohammed VI Polytechnic University de Benguerir, Morocco and OCP group. We thank our colleagues from university who provided insight and expertise that greatly assisted the research.

\section{REFERENCES}

[1] M. Sony, "Industry 4.0 and lean management: a proposed integration model and research propositions," Production \& Manufacturing Research, vol. 6, no. 1, pp. 416-432, Jan. 2018, doi: 10.1080/21693277.2018.1540949.

[2] L. D. Xu, E. L. Xu, and L. Li, "Industry 4.0: state of the art and future trends," International Journal of Production Research, vol. 56, no. 8, pp. 2941-2962, Apr. 2018, doi: 10.1080/00207543.2018.1444806.

[3] B. Rodič, "Industry 4.0 and the New Simulation Modelling Paradigm," Organizacija, vol. 50, no. 3, pp. 193-207, Aug. 2017, doi: 10.1515/orga2017-0017.

[4] Y. Cheng, K. Chen, H. Sun, Y. Zhang, and F. Tao, "Data and knowledge mining with big data towards smart production," Journal of Industrial Information Integration, vol. 9, pp. 1-13, Mar. 2018, doi: 10.1016/j.jii.2017.08.001.

[5] L. Cavanini et al., "A Preliminary Study of a Cyber Physical System for Industry 4.0: Modelling and Co-Simulation of an AGV for Smart Factories," in 2018 Workshop on Metrology for Industry 4.0 and IoT, Brescia, 2018, pp. 169-174, doi: 10.1109/METROI4.2018.8428334.

[6] A. Wortmann, B. Combemale, and O. Barais, "A Systematic Mapping Study on Modeling for Industry 4.0," in 2017 ACM/IEEE 20th International Conference on Model Driven Engineering Languages and Systems (MODELS), Austin, TX, 2017, pp. 281-291, doi: 10.1109/MODELS.2017.14.

[7] J. Dizdarevic, F. Carpio, A. Jukan, and X. Masip-Bruin, "Survey of Communication Protocols for Internet-of-Things and Related Challenges of Fog and Cloud Computing Integration," ACM Computing Surveys, vol. 51, no. 6, pp. 1-29, Jan. 2019, doi: 10.1145/3292674.

[8] R. Petrasch and R. Hentschke, "Process modeling for industry 4.0 applications: Towards an industry 4.0 process modeling language and method," in 2016 13th International Joint Conference on Computer Science and Software Engineering (JCSSE), Khon Kaen, Thailand, 2016, pp. 1-5, doi: 10.1109/JCSSE.2016.7748885.

[9] L. S. Dalenogare, G. B. Benitez, N. F. Ayala, and A. G. Frank, "The expected contribution of Industry 4.0 technologies for industrial performance," International Journal of Production Economics, vol. 204, pp. 383-394, Oct. 2018, doi: 10.1016/j.ijpe.2018.08.019.

[10] S. Belkhala, S. Benhadou, K. Boukhdir, and H. Medromi, "Smart Parking Architecture based on Multi Agent System," International Journal of Advanced Computer Science and Applications, vol. 10, no. 3, 2019, doi: 10.14569/IJACSA.2019.0100349.

[11] M. W. Grieves, "Product lifecycle management: the new paradigm for enterprises," International Journal of Product Development, vol. 2, no. 1/2, p. 71, 2005, doi: 10.1504/IJPD.2005.006669.

[12] OCP Group, “2017 Annual report OCP Group,” 2017.
[13] "Webcast: Dr. Michael Grieves - Digital Twin: Manufacturing Excellence through Virtual Factory Replication.” [Online]. Available: http://www.apriso.com/library/video/dr_grieves_digital_twin_webcast_e n.php. [Accessed: 06-Apr-2019].

[14] M. Grieves and J. Vickers, "Digital Twin: Mitigating Unpredictable, Undesirable Emergent Behavior in Complex Systems," in Transdisciplinary Perspectives on Complex Systems, F.-J. Kahlen, S. Flumerfelt, and A. Alves, Eds. Cham: Springer International Publishing, 2017, pp. 85-113.

[15] E. Glaessgen and D. Stargel, "The Digital Twin Paradigm for Future NASA and U.S. Air Force Vehicles," in 53rd AIAA/ASME/ASCE/AHS/ASC Structures, Structural Dynamics and Materials Conference, American Institute of Aeronautics and Astronautics.

[16] S. Weyer, T. Meyer, M. Ohmer, D. Gorecky, and D. Zühlke, "Future Modeling and Simulation of CPS-based Factories: an Example from the Automotive Industry," IFAC-PapersOnLine, vol. 49, no. 31, pp. 97-102, 2016, doi: 10.1016/j.ifacol.2016.12.168.

[17] F. Yao, A. Keller, M. Ahmad, B. Ahmad, R. Harrison, and A. W. Colombo, "Optimizing the Scheduling of Autonomous Guided Vehicle in a Manufacturing Process," in 2018 IEEE 16th International Conference on Industrial Informatics (INDIN), Porto, 2018, pp. 264269, doi: 10.1109/INDIN.2018.8471979.

[18] K. Reifsnider and P. Majumdar, "Multiphysics Stimulated Simulation Digital Twin Methods for Fleet Management," in 54th AIAA/ASME/ASCE/AHS/ASC Structures, Structural Dynamics, and Materials Conference, Boston, Massachusetts, 2013, doi: 10.2514/6.2013-1578.

[19] "Digital Twin Technology Can Make Smart Cities Even Smarter." [Online]. Available: https://www.govtech.com/smart-cities/DigitalTwin-Technology-Can-Make-Smart-Cities-Even-Smarter.html. [Accessed: 18-Dec-2019].

[20] N. Mohammadi and J. E. Taylor, "Smart city digital twins," in 2017 IEEE Symposium Series on Computational Intelligence (SSCI), Honolulu, HI, 2017, pp. 1-5, doi: 10.1109/SSCI.2017.8285439.

[21] R. Martinez-Velazquez, R. Gamez, and A. E. Saddik, "Cardio Twin: A Digital Twin of the human heart running on the edge," in 2019 IEEE International Symposium on Medical Measurements and Applications (MeMeA), Istanbul, Turkey, 2019, pp. 1-6, doi: 10.1109/MeMeA.2019.8802162.

[22] R. Lutze, "Digital Twins in eHealth -: Prospects and Challenges Focussing on Information Management," in 2019 IEEE International Conference on Engineering, Technology and Innovation (ICE/ITMC), Valbonne Sophia-Antipolis, France, 2019, pp. 1-9, doi: 10.1109/ICE.2019.8792622.

[23] S. Boschert and R. Rosen, "Digital Twin-The Simulation Aspect," in Mechatronic Futures, P. Hehenberger and D. Bradley, Eds. Cham: Springer International Publishing, 2016, pp. 59-74.

[24] F. Tao, M. Zhang, and A. Y. C. Nee, "Background and Concept of Digital Twin," Elsevier, 2019, pp. 3-28.

[25] A. Detzner and M. Eigner, "A DIGITAL TWIN FOR ROOT CAUSE ANALYSIS AND PRODUCT QUALITY MONITORING," DS 92: Proceedings of the DESIGN 2018 15th International Design Conference, 2018. [Online]. Available: https://www.designsociety.org/publication 140558/A+DIGITAL+TWIN+FOR+ROOT+CAUSE+ANALYSIS+AN D+PRODUCT+QUALITY+MONITORING. [Accessed: 14-May-2019].

[26] F. Tao, J. Cheng, Q. Qi, M. Zhang, H. Zhang, and F. Sui, "Digital twindriven product design, manufacturing and service with big data," Int $\mathbf{J}$ Adv Manuf Technol, vol. 94, no. 9-12, pp. 3563-3576, Feb. 2018, doi: 10.1007/s00170-017-0233-1.

[27] P. André, F. Azzi, and O. Cardin, "Heterogeneous Communication Middleware for Digital Twin Based Cyber Manufacturing Systems," in Service Oriented, Holonic and Multi-agent Manufacturing Systems for Industry of the Future, vol. 853, T. Borangiu, D. Trentesaux, P. Leitão, A. Giret Boggino, and V. Botti, Eds. Cham: Springer International Publishing, 2020, pp. 146-157.

[28] K. Borodulin, G. Radchenko, A. Shestakov, L. Sokolinsky, A. Tchernykh, and R. Prodan, "Towards Digital Twins Cloud Platform: Microservices and Computational Workflows to Rulea Smart Factory," 
in Proceedings of the10th International Conference on Utility and Cloud Computing - UCC '17, Austin, Texas, USA, 2017, pp. 209-210, doi: $10.1145 / 3147213.3149234$.

[29] A. Ebrahimi, "Challenges of developing a digital twin model of renewable energy generators," in 2019 IEEE 28th International Symposium on Industrial Electronics (ISIE), Vancouver, BC, Canada, 2019, pp. 1059-1066, doi: 10.1109/ISIE.2019.8781529.

[30] K. Josifovska, E. Yigitbas, and G. Engels, "Reference Framework for Digital Twins within Cyber-Physical Systems," in 2019 IEEE/ACM 5th International Workshop on Software Engineering for Smart CyberPhysical Systems (SEsCPS), Montreal, QC, Canada, 2019, pp. 25-31, doi: 10.1109/SEsCPS.2019.00012.

[31] H. Yoo and T. Shon, "Challenges and research directions for heterogeneous cyber-physical system based on IEC 61850: Vulnerabilities, security requirements, and security architecture," Future Generation Computer Systems, vol. 61, pp. 128-136, Aug. 2016, doi: 10.1016/j.future.2015.09.026.

[32] M. Schluse and J. Rossmann, "From simulation to experimentable digital twins: Simulation-based development and operation of complex technical systems," in 2016 IEEE International Symposium on Systems Engineering (ISSE), Edinburgh, United Kingdom, 2016, pp. 1-6, doi: 10.1109/SysEng.2016.7753162.

[33] T. Borangiu, D. Trentesaux, A. Thomas, P. Leitão, and J. Barata, "Digital transformation of manufacturing through cloud services and resource virtualization," Computers in Industry, vol. 108, pp. 150-162, Jun. 2019, doi: 10.1016/j.compind.2019.01.006.

[34] "Digital twin of cost," Siemens PLM Software. [Online]. Available: https://www.plm.automation.siemens.com/global/fr/topic/digital-twinof-cost/60535. [Accessed: 22-Nov-2019].

[35] Z. Song and A. M. Canedo, "Digital twins for energy efficient asset maintenance," US20160247129A1, 25-Aug-2016.

[36] "Connected Plant - Honeywell." [Online]. Available: https://www honeywellprocess.com/en-US/online_campaigns/connected_plant/Pages /home.html. [Accessed: 17-Apr-2019].

[37] K. Lee, "Digital Transformation using Digital Twins," p. 37, 2018.

[38] J. E. Hershey, F. W. Wheeler, M. C. Nielsen, C. D. Johnson, M. J. Dell'Anno, and J. JOYKUTTI, "Digital twin of twinned physical system," US20170286572A1, 05-Oct-2017.

[39] Arnold M. Lund, Oakland, CA (US); et al., "DIGITAL TWIN INTERFACE FOR OPERATING WIND FARMS," 17-Nov-2016.

[40] "What Is Digital Twin Technology? | PTC." [Online]. Available: https://www.ptc.com/en/product-lifecycle-report/what-is-digital-twintechnology. [Accessed: 20-May-2019].

[41] Gerald Les Vossler, Grand Rapids, MI (US), "NETWORK FOR DIGITAL EMULATION AND REPOSITORY," 30-Jun-2016.

[42] Edward A. Fowler, Houston, TX ( US, "DIGITAL TWIN OF CENTRIFUGAL PUMP IN PUMPING SYSTEMS," 20-Jun-2019.

[43] "The Digital Twin: Creating digital operations today to deliver business value tomorrow," Altran United Kingdom. [Online]. Available: https://www.altran.com/uk/en/insight/the-digital-twin-how-to-createvalue-now-and-prepare-for-digital-operations-for-tomorrow/. [Accessed: 22-Nov-2019].

[44] "Digital Twin towards a meaningful framework - Arup." [Online]. Available:

https://www.arup.com/perspectives/publications/research/section/digitaltwin-towards-a-meaningful-framework. [Accessed: 25-Dec-2019].

[45] Q. Li et al., "Smart manufacturing standardization: Architectures, reference models and standards framework," Computers in Industry, vol. 101, pp. 91-106, Oct. 2018, doi: 10.1016/j.compind.2018.06.005.

[46] A. J. C. Trappey, C. V. Trappey, U. H. Govindarajan, J. J. Sun, and A. C. Chuang, "A Review of Technology Standards and Patent Portfolios for Enabling Cyber-Physical Systems in Advanced Manufacturing," IEEE Access, vol. 4, pp. 7356-7382, 2016, doi: 10.1109/ACCESS.2016.2619360.

[47] M. Helu, A. Joseph, and T. Hedberg, "A standards-based approach for linking as-planned to as-fabricated product data," CIRP Annals, vol. 67, no. 1, pp. 487-490, 2018, doi: 10.1016/j.cirp.2018.04.039.

[48] 14:00-17:00, “ISO/CD 23247-1," ISO. [Online]. Available: http://www.iso.org/cms/render/live/en/sites/isoorg/contents/data/standar d/07/50/75066.html. [Accessed: 26-Oct-2019].

[49] B. Melzer, "Reference Architectural Model Industrie 4.0 (RAMI 4.0)," p. 15.

[50] B. Melzer, "Reference Architectural Model Industrie 4.0 (RAMI 4.0)," p. 15.

[51] R. Leszczyna, "A review of standards with cybersecurity requirements for smart grid," Computers \& Security, vol. 77, pp. 262-276, Aug. 2018, doi: 10.1016/j.cose.2018.03.011.

[52] G. N. Schroeder, C. Steinmetz, C. E. Pereira, and D. B. Espindola, "Digital Twin Data Modeling with AutomationML and a Communication Methodology for Data Exchange," IFACPapersOnLine, vol. 49, no. 30, pp. 12-17, 2016, doi: 10.1016/j.ifacol.2016.11.115.

[53] L. F. C. S. Durão, S. Haag, R. Anderl, K. Schützer, and E. Zancul, "Digital Twin Requirements in the Context of Industry 4.0," in Product Lifecycle Management to Support Industry 4.0, vol. 540, P. Chiabert, A. Bouras, F. Noël, and J. Ríos, Eds. Cham: Springer International Publishing, 2018, pp. 204-214.

[54] M. Rodríguez, J. R. Oviedo, and M. Piattini, "Evaluation of Software Product Functional Suitability: A Case Study," p. 12.

[55] S. Elnagar, H. Weistroffer, and M. Thomas, "Agile Requirement Engineering Maturity Framework for Industry 4.0," in Information Systems, vol. 341, M. Themistocleous and P. Rupino da Cunha, Eds. Cham: Springer International Publishing, 2019, pp. 405-418.

[56] M. Yli-Ojanperä, S. Sierla, N. Papakonstantinou, and V. Vyatkin, "Adapting an agile manufacturing concept to the reference architecture model industry 4.0: A survey and case study," Journal of Industrial Information Integration, Dec. 2018, doi: 10.1016/j.jii.2018.12.002.

[57] "Livre Blanc: La Transformation Digitale Au Maroc. - AUSIM MAROC." [Online]. Available: http://www.ausimaroc.com/livre-blancla-transformation-digitale-au-maroc/. [Accessed: 29-Dec-2019].

[58] S. El Hamdi, M. Oudani, and A. Abouabdellah, "Morocco's Readiness to Industry 4.0," in Proceedings of the 8th International Conference on Sciences of Electronics, Technologies of Information and Telecommunications (SETIT'18), Vol.1, vol. 146, M. S. Bouhlel and S. Rovetta, Eds. Cham: Springer International Publishing, 2020, pp. 463472.

[59] T. D. West and A. Pyster, "Untangling the Digital Thread: The Challenge and Promise of Model-Based Engineering in Defense Acquisition," INSIGHT, vol. 18, no. 2, pp. 45-55, Aug. 2015, doi: 10.1002/inst. 12022.

[60] J. Hereu, "1. SMART CITY EXPO CASABLANCA, ED. 20182. VILLES À VIVRE ET INNOVATION CITOYENNE 3. TEMPS FORTS A. DISCOURS 1 LA SMART CITY EN TANT QUE PROJET," p. 50.

[61] Z. Boudanga, S. Benhadou, H. Medromi, and J.-P. Leroy, "Development perspective of a Moroccan smart city," in 2019 Third World Conference on Smart Trends in Systems Security and Sustainablity (WorldS4), London, United Kingdom, 2019, pp. 247-254, doi: 10.1109/WorldS4.2019.8903961.

[62] Weltwirtschaftsforum and A. T. Kearney Incorporated, Readiness for the future of production report 2018. 2018.

[63] "SIMIT Simulation Platform (V9.1)," p. 876. 